\title{
INSTAGRAM E ELEIÇÕES: OS STORIES DOS PRESIDENCIÁVEIS DO BRASIL EM 2018
}

Instagram and elections: the stories of Brazil's presidential candidates in 2018 Instagram y las elecciones: los stories de los candidatos presidenciales de
Brasil en 2018

Rafael Cardoso Sampaio Professor/Pesquisador (PPGCP-UFPR) cardososampaio@gmail.com

Gabriel Alexandre Bozza Professor (Unibrasil e PUCPR)/Doutorando(PPGCP-UFPR) gabrielbozz@gmail.com

Murilo Brum Alison Mestrando (PPGCP-UFPR) murilo43@hotmail.com

Djiovanni Jonas França Marioto

Mestrando (PPGCP-UFPR) djiovannimarioto@gmail.com

Tiago Philippini Ferreira Borges da Silva

Mestrando (PPGCP-UFPR) tpfbsilva@gmail.com

\section{Resumo}

O objetivo do artigo é analisar as estratégias de uso dos stories do Instagram postados pelos candidatos à Presidência da República do Brasil em 2018. As nossas hipóteses de pesquisa são que os candidatos usaram os stories para enaltecer sua imagem pessoal e anunciar agenda de campanha (H1), e houve alto uso dos stories para divulgar bastidores e baixo uso para propostas de campanha $(\mathrm{H} 2)$. Os stories foram classificados em seis variáveis elaboradas: tema geral, tema específico, tema secundário, tipo de imagem, menção a partido e humor. A coleta $(\mathrm{N}=2032)$ foi realizada entre 05 de setembro e 07 de outubro de 2018, compreendendo o primeiro turno das eleições. Procedemos a uma análise de conteúdo do tipo quantitativa e qualitativa por meio de um livro de códigos. Os resultados sugerem que os candidatos usaram a plataforma para gerenciar imagem pública e anúncio de agenda.

Palavras-chave: Instagram. Stories. Presidente. 


\begin{abstract}
This article aims to analyze the strategies for using Instagram stories posted by presidential candidates in the Republic of Brazil in 2018. Our research hypotheses are that candidates used the stories to enhance their personal image and announce campaign agenda $(\mathrm{H} 1)$, and there was a high use of stories to promote backstage, and low usage for campaign proposals $(\mathrm{H} 2)$. The stories were classified into six elaborated variables: general theme, specific theme, secondary theme, image type, party mention and humor. To do this, we collected stories $(\mathrm{N}=2032)$ from the Instagram social networking application from September 5 to October 7 , 2018 , comprising the first round of elections. We proceed to a quantitative and qualitative content analysis using a codebook. The results suggest that the candidates used the platform to manage public image and calendar announcement.
\end{abstract}

Key words: Instagram. Stories. President.

\title{
Resumen
}

El objetivo es analizar las estrategias para usar las historias de Instagram publicadas por los candidatos presidenciales en la República de Brasil en 2018. Nuestras hipótesis de investigación son que los candidatos usaron las historias para mejorar su imagen personal y anunciar la agenda de la campaña. (H1), y hubo un gran uso de historias para extenderse entre bastidores, y bajo uso para propuestas de campaña (H2). Las historias se clasificaron en seis variables elaboradas: tema general, tema específico, tema secundario, tipo de imagen, mención de partido y humor. La recolección se realizo entre 5 de septiembre y 7 de octubre de 2018, que comprende la primera ronda de elecciones. Procedemos a un análisis de contenido cuantitativo y cualitativo utilizando un libro de códigos. Los resultados sugieren que los candidatos utilizaron la plataforma para administrar la imagen pública y el anuncio del calendário.

Palabras clave: Instagram. Stories. Presidente.

\section{INTRODUÇÃO}

As plataformas de redes sociais digitais têm possibilitado aos diferentes indivíduos estabelecer relações com diferentes atores, expressar emoções, demonstrar suas vontades, mobilizar e engajar públicos amplos a partir de suas arquiteturas (BOSSETTA, 2018; WATERLOO et. al, 2017). Da mesma forma, elas são uma oportunidade dos candidatos e partidos políticos conquistarem votos em períodos eleitorais, a partir de estratégias de aproximação, humanização e persuasão nos ambientes digitais com o incentivo a circulação de informações, produção, expansão e compartilhamento de conteúdo (FILIMONOV, RUSSMANN，SVENSSON，2016; LALANCETTE，RAYNAULD，2017; SELVA-RUIZ, CARO-CASTAÑO, 2017; TURNBULL-DUGARTE, 2019).

$\mathrm{O}$ incentivo a uma maior ecologia midiática permite aos atores políticos encontrar diferentes possibilidades de engajamento dos eleitores. As eleições presidenciais de 2018 consolidaram fenômenos oriundos de campanhas digitais em 2010, como a crescente 
polarização política assimétrica, radicalização política ideológica da direita, o forte uso de diferentes redes sociais digitais para interação e aproximação com o eleitorado, observadas anteriormente por estudiosos, e tornadas gradativamente mais profissionalizadas e centrais nesta campanha (BRAGA, CARLOMAGNO, 2018; CERVI, MASSUCHIN, CARVALHO, 2016; BRUGNANO, CHAIA, 2014; LARREA, 2010; MARQUES, AGGIO, SAMPAIO, 2013; GOMES, 2018).

As campanhas profissionalizadas observaram a oportunidade de ampliar a visibilidade digital de seus candidatos pelo uso exponencial das redes sociais digitais por eleitores consumidas por dispositivos móveis inteligentes. Por sua própria estrutura e lógica de organização, tais redes permitem que os conteúdos elaborados pelas campanhas atinjam uma exposição pública sem que haja a necessidade de serem acionados diretamente pelas campanhas (AGGIO; REIS, 2013). Formas de usos e estratégias diferentes são adotadas nas redes sociais digitais, conservadas suas affordances. O Twitter e Facebook mantiveram nas eleições 2018 suas hegemonias como redes sociais centrais de compartilhamento de conteúdo. O YouTube permaneceu como principal repositório de vídeos. Porém agora parte significativa do conteúdo foi distribuída de maneira direta pelo WhatsApp, e o Instagram passou a ser outro ambiente para tanto moldar a imagem do candidato quanto criar uma aproximação e relacionamento com os eleitores.

$\mathrm{Na}$ esfera pública digital, houve excesso de campanha negativa com algoritmos, principalmente, o uso de robôs sociais (bots) para privilegiar candidatos e atacar adversários, os filtros-bolha (filter bubble) que customizam vontades ao usuário e formam bolhas, a criação e proliferação de notícias falsas (fake news) para desinformação política, e as deep fakes para destruir a honra e imagem pública de concorrentes. Os meios de comunicação tiveram intensa atuação na checagem de fatos, e os partidos políticos criaram mecanismos para combate as fake news (BRAGA, WISSE, BOZZA, 2018).

Além disso, a minirreforma eleitoral aprovada em 2015 impactou em duas mudanças significativas na forma de organização das campanhas na última eleição presidencial. Houve a proibição das doações de empresas para as campanhas reduzindo os investimentos. Assim como o tempo das campanhas e do HGPE foi diminuído de 45 dias e 25 minutos de duração em 2014 para 35 dias e 12 minutos e 30 segundos em 2018. Consideramos ainda que os debates televisivos perderam parte de sua a importância sem o candidato Jair Bolsonaro, ausente após sofrer ataque a sua vida. 
A partir deste contexto eleitoral, o objetivo proposto neste artigo é analisar a forma de construção das campanhas dos candidatos a partir dos stories, postados, no aplicativo de rede social Instagram, pelos candidatos à Presidência da República nas eleições de 2018. Para isso, nosso objeto contempla um corpus empírico composto por 2032 stories coletados das contas oficiais de sete candidatos entre os dias 05 de setembro e 07 de outubro de 2018 , durante o primeiro turno da disputa presidencial, conforme a tabela 1 a seguir:

Tabela 1 - Candidatos, partidos e contas no Instagram

\begin{tabular}{ccc}
\hline Candidato & Partido Político & Conta no Instagram \\
\hline Ciro Gomes & PDT & @ cirogomes \\
\hline Fernando Haddad & PT & @ fernandohaddadoficial \\
\hline Geraldo Alckmin & PSDB & @ henriquemeirelles.real \\
\hline Henrique Meirelles & MDB & @ jairmessiasbolsonaro \\
\hline Jari Bolsonaro & PSL & @ joaoamoedonovo \\
\hline Joao Amoêdo & NOVO & @ marinasilva.18 \\
\hline Marina Silva & REDE & \\
\hline
\end{tabular}

Fonte: Elaboração dos autores (2019)

A seleção dos candidatos levou em conta a presença deles à frente das pesquisas de intenção de voto e a quantidade de seguidores em seus perfis no Instagram. Conforme aponta a pesquisa de Ruediger e Grassi (2018), Redes Sociais nas Eleições de 2018, os candidatos tiveram incremento significativo de usuários na campanha eleitoral observado do início da campanha até meados de setembro.

João Amoêdo foi o presidenciável que mais cresceu no Instagram no primeiro mês de campanha oficial, de acordo com levantamento da FGV DAPP, realizado entre 14 de agosto e 13 de setembro. O perfil do candidato passou de 136,3 mil para 452,5 mil seguidores, o que representa cerca de $230 \%$ de aumento. A ampliação da base na rede levou Amoêdo ao segundo lugar em total de seguidores, atrás apenas de Jair Bolsonaro, que acumulou 2,6 milhões de seguidores, volume quase seis vezes maior que o do candidato do Novo. Fernando Haddad ocupa a segunda posição em crescimento, passando de 104,7 mil para 230,3 mil seguidores (quase $120 \%$ de elevação). Apesar do aumento expressivo, Haddad ficou em $4^{\circ}$ lugar em volume total de seguidores, ainda distante de Ciro Gomes que acumulava, no 
período analisado, 312,4 mil seguidores, resultado do crescimento de 76,2\% em sua base na rede desde o início da coleta dos dados. (RUEDIGER; GRASSI, 2018, p. 24).

A mídia Instagram foi escolhida por ter uma crescente participação na maneira que a população consome imagens e aprecia a vida cotidiana de outros indivíduos, em conjunto com a larga utilização dessa ferramenta pelos candidatos. Levamos em consideração a evolução de seu uso em campanhas digitais para discussão pública e na formação de opinião pública. Salientamos ainda a baixa produção científica sobre Instagram e eleições.

Sendo assim, a nossa questão de pesquisa (Q1) é: quais as estratégias usadas pelas campanhas profissionalizadas na ferramenta stories do Instagram dos candidatos à Presidência da República no Brasil em 2018? As hipóteses de pesquisa são que os candidatos usaram os stories para enaltecer sua imagem pessoal e anunciar agenda de campanha (H1), e houve alto uso dos stories para divulgar bastidores; baixo uso para propostas de campanha $(\mathrm{H} 2)$.

$\mathrm{Na}$ primeira seção, realizamos uma breve revisão da literatura sobre Instagram, eleições e imagem na plataforma de rede social digital. Subsequentemente, expomos o procedimento metodológico usado nesse artigo com o detalhamento dos métodos usados para coleta e codificação. Por fim, descrevemos os significados dos resultados empíricos obtidos.

\section{INSTAGRAM E ELEIÇÕES}

A pesquisa do Instagram e sua relação com a comunicação político-eleitoral nacional é um fenômeno recente. Apesar disso, o Instagram é a quarta rede social digital mais usada no Brasil. Hoje possui mais de um bilhão de usuários no mundo, segundo dados do $\operatorname{Statista~}^{1}$ e Global Digital $(2019)^{2}$. Ela foi criada em outubro de 2010 como um novo formato de rede para postagem de imagens por meio do celular iPhone, posteriormente adotada por usuários de diferentes smartphones, para o compartilhamento de curtos vídeos e imagens, comentários, e interação de usuários similar ao Twitter (FILIMONOV, RUSSMANN, SVENSSON, 2016; TOWNER, MUÑOZ, 2017; YU, MANIKONDA, KAMPHAMPATI, 2014). Em 2012, a plataforma foi adquirida pelo Facebook e expandiu negócios e número de usuários.

\footnotetext{
${ }^{1}$ STATISTA. Disponível em: https://www.statista.com/statistics/272014/global-social-networks-ranked-bynumber-of-users/. Acesso em: 05 jul. 2019.

${ }^{2}$ GLOBAL DIGITAL. We Are Social. 2019. Disponível em: https://wearesocial.com/global-digital-report-2019. Acesso em: 05 jul. 2019.
} 
Esta rede social digital permite o compartilhamento de vídeos, infográficos, GIFs e imagens. Incentiva a utilização de filtros para alterar cores e contrastes, inclusão de símbolos, emojis, hashtags, usertags ou tags de geolocalização e a construção de uma arquitetura de informação convergente entre mídias. As imagens podem ou não ser legendadas, permitindo nas suas funções postagens com comentários e curtidas e adição de seguidores (PARMELEE, ROMAN, 2019; RUSSMANN, SVENSSON, 2016). Sendo assim, “[...] Instagram favorece em seu desenho de interação a percepção de mobilidade, instantaneidade e autenticidade na comunicação visual”3 (SELVA-RUIZ, CARO-CASTAÑO, 2017, p. 904, grifo dos autores, tradução nossa).

Em 2016, a plataforma criou a opção Insta stories, composta por vídeos de curta duração que são automaticamente apagados 24 horas após serem publicados, geralmente usados pelas celebridades para fazer pequenas aparições ao vivo (i.e. lives) para seus seguidores. Além disso, os vloggers de beleza, moda e entretenimento e aparições públicas de celebridades permeiam o IGTV, uma TV do Instagram, como estratégia de marketing digital.

O uso da plataforma de mídia social Instagram por partidos, candidatos e eleitores como kit em eleições presidenciais ocorre desde 2012, notadamente por Barack Obama e sua família nas eleições norte-americanas, e seus efeitos em contextos eleitorais são objeto de atenção por diversos pesquisadores que buscam compreender o uso das formas, usos e efeitos, seja na construção de narrativas textuais e visuais, storytelling, entendimento do papel dos influenciadores e celebridades, formas de engajamento, as emoções, entre outros fenômenos (BENNETT, 2016; EKMAN, WIDHOLM, 2017; LIEBHART, BERNHARDT, 2017; SCHILL, 2012; TOWNER, MUÑOZ, 2017; TURNBULL-DUGARTE, 2019; WATERLOO et al., 2017).

No Instagram, Filimonov, Russmann e Svensson (2016) e Larsson (2017), por exemplo, analisam as eleições suecas e norueguesas, respectivamente, O'Connell (2018) e Selva-Ruiz, Caro-Castaño (2017) investigam o comportamento, presença e backstage de congressistas americanos e espanhóis, respectivamente, e Schmidbauer, Rosch, Stieler (2017) estudam o uso de hashtags nas eleições americanas em 2016. No geral, as pesquisas com o Instagram em ambientes eleitorais estão concentradas no sentido de transmissão de mensagens eleitorais, mobilização de apoiadores, gerenciamento da imagem do partido e 
ampliação e complementariedade de outros materiais de campanha (FILIMONOV, RUSSMANN, SVENSSON, 2016).

Em suma, as pesquisas se concentraram mais em apontar os usos do que os significados do plano visual-imagético, sendo necessário perceber que as imagens são argumentos e influenciam as nossas discussões políticas e compreender como o Instagram funciona na comunicação política (LIEBHART, BERNHARDT, 2017; LÓPEZ-RABADÁN, DOMÉNECH-FABREGAT, 2018; MUÑOZ, TOWNER, 2017; SCHILL, 2012).

As campanhas políticas são diferentes no sentido em que possuem alta capacidade de estratégias, cujo objetivo é a persuasão e mobilização de apoiadores para vencer as eleições (FILIMONOV, RUSSMANN, SVENSSON, 2016). A força política do uso do Instagram é inclusive apontada por Glantz (2013):

Os elogios que o Instagram recebeu como ferramenta de comunicação política tendeu a se concentrar em como fornecer ao político um método direto e conciso de compartilhamento e aprimoramento de sua mensagem e como ajudar os cidadãos a se sentirem pessoalmente conectados ao governo e seus líderes. (GLANTZ, 2013, p. 695, tradução nossa)

Um estudo da eleição sueca mostra que os candidatos usaram em 2014 a plataforma de rede social digital mais como "panfleto virtual" ao invés de mobilização (FILIMONOV, RUSSMANN, SVENSSON, 2016). Entretanto, existem hábeis utilizadores de redes sociais digitais. Barack Obama, por exemplo, usou o Instagram nas eleições estadunidenses como portfólio de seus encontros e viagens políticas. As imagens captadas pelos meios de comunicação tradicionais não seriam capazes de demonstrar esse movimento do candidato. Suas aparições, assim como de outros candidatos observados em pesquisas mundiais, misturam o auto-selfie com a vida privada mesclada a vida profissional como forma de gerar intimidade e conectividade.

Os recursos do Instagram auxiliam ainda na defesa política, com usuários podendo marcar líderes políticos, enviar mensagem direta, e curtir mensagens desses atores para aumentar a popularidade e liderança (PARMELEE, ROMAN, 2019). Atualmente, destacamos que os posts e stories sobre temas políticos e eleitorais, por exemplo, devem trazer informações sobre quem pagou por ele a partir da descrição de pago abaixo do vídeo ou foto com a citação do patrocinador. 


\section{IMAGEM E COMUNICAÇÃO POLÍTICA NO INSTAGRAM}

Estudos mostram a importância da imagem de um político na busca e avaliação de uma liderança política com requisitos como honestidade, simpatia, sinceridade, confiança e inteligência (LALANCETTE, RAYNAULD, 2017). O Instagram se apoia na lógica da “imagem em primeiro lugar" com grande capacidade performática dos usuários, enfatizando novas técnicas e modos de comunicação política (EKMAN, WIDHOLM, 2017, p. 18-19). As peças gráficas usam composição de elementos para atrair e persuadir os eleitores como estratégias de campanha permanente e, conforme cita Waterloo et al. (2017), as plataformas, como o Instagram, incentivam a auto-expressão emocional positiva ou negativa.

Plataformas para compartilhar imagens, a exemplo do Instagram, revelam novas regras, habilidades, dimensões, capacidades e realidades que convergem conversações entre o offline e online por meio de mensagens verbais e visuais. Russmann e Svensson (2016) apontam características presentes no Instagram, tais como: perspectiva, difusão, mobilização, gerenciamento de imagem, personalização, celebridades, privatização, hibridismo e interatividade. López-Rabadán e Doménech-Fabregat (2018), por exemplo, sugerem um modelo similar ao 5W jornalístico para analisar eleições espanholas composto por características como: tema e função principal da imagem, protagonista e ator secundário da imagem, atributos, espaço da imagem, cena, tipo de apelação e aspectos técnicos.

As imagens são componentes basilares na comunicação política, quando criadas e criativas elas possuem a capacidade de dramatizar, apelar ao emocional, criar símbolos identitários, por meio de controle de iluminação, expressão facial do ator político, plano de fundo e cenário na influência da opinião pública (PARMELEE, ROMAN, 2019; SCHILL, 2012). Elas constroem reputações e são criadas “[...] a partir do uso de impressões visuais comunicadas pela presença física do candidato, aparições na mídia, experiências e registros da mídia, à medida que essas informações são integradas às mentes dos cidadãos" (NEWMAN, 1999, p. 92, tradução nossa). Para uma boa reputação as multidões ajudam a mostrar a popularidade de um candidato, o amplo apoio e sua força política (SCHILL, 2012).

No estreitamento dos vínculos afetivos, o relacionamento intensificado busca criar imagem pública positiva do ator político entre os indivíduos nas redes sociais digitais. Ocorre uma modelagem de imagem para nichos específicos de público, e são acessíveis emocionalmente e intelectualmente pelos indivíduos, e numa concorrência entre atores políticos à busca pela relevância das mensagens e credibilidade nas imagens (BENNETT, 2016). 
As imagens são construídas em diferentes espaços físicos por candidatos, sejam hospitais, zonas agrícolas, em caminhadas, em encontros com setores industriais e comerciais e, conforme aponta Schill (2012), possibilitam adequar o candidato ao cargo, suas qualidades e posições sobre os cenários. O Instagram é usado para o gerenciamento da imagem pública e compartilhamento de materiais de campanha e a personalização nas postagens fortalecem os principais candidatos (FILIMONOV, RUSSMANN, SVENSSON, 2016).

\section{DADOS E MÉTODOS DE PESQUISA}

Os stories foram coletados dos perfis oficiais de cada um dos sete candidatos à presidência apresentados anteriormente. Para isso foi utilizado o software $4 \mathrm{~K}$ Stogram e definido um horário diário de coleta. No final obtivemos um total de 2032 arquivos no período entre 05 de setembro e 07 de outubro de 2018. Por seguinte organizamos as mídias baixadas em pastas, separando-as por candidato e data, e buscando facilitar a montagem e organização da tabela de classificação. Para a tabulação, fizemos utilização de análise de conteúdo do tipo quantitativa e qualitativa baseada em um livro de códigos elaborado.

A seguir, trazemos os primeiros dados da pesquisa que permitem uma verificação de parâmetro geral para, por fim, compreender e destacar as características predominantes no uso dos stories de cada um dos candidatos. Conforme observamos abaixo (TABELA 2), o candidato Fernando Haddad (PT) produziu quase um terço dos stories durante a campanha eleitoral no primeiro turno; enquanto Marina Silva (REDE) e Jair Bolsonaro (PSL) pouco usaram o recurso do Instagram.

Tabela 2 - Total de stories analisados por candidatos

\begin{tabular}{cccc}
\hline Candidato & Partido Político & $\mathbf{N}$ & $\%$ \\
\hline Fernando Haddad & PT & 644 & $30 \%$ \\
\hline Henrique Meirelles & MDB & 365 & $18 \%$ \\
\hline Geraldo Alckmin & PSDB & 300 & $14,8 \%$ \\
\hline Joao Amoêdo & NOVO & 268 & $13,2 \%$ \\
\hline Ciro Gomes & PDT & 236 & $11,6 \%$ \\
\hline Jair Bolsonaro & PSL & 156 & $7,7 \%$ \\
\hline
\end{tabular}




\begin{tabular}{cccc}
\hline Marina Silva & REDE & 63 & $3,1 \%$ \\
\hline & Total & 2032 & $100 \%$ \\
\hline
\end{tabular}

Fonte: Elaboração dos autores (2019).

Definida a quantidade de stories $(\mathrm{N}=2032)$, passamos a classificação deles por seis variáveis: 1) Tema Geral; 2) Tema Específico; 3) Tema Secundário; 4) Tipo de imagem; 5) Menção a partido; e 6) Humor. É importante destacar que o tema secundário não recebeu classificação em 968 casos (quase metade do total), com isso é relevante lembrar que os stories do Instagram têm uma duração de no máximo 15 segundos, o que dificulta o candidato tratar de mais temas em apenas um story, sendo esta ausência um resultado esperado. Devemos destacar que a análise, em caso de vídeos com narrativa única, se deu de forma fracionada; ou seja, contamos como stories separados. As últimas duas variáveis eram de caráter dummy, ou seja, tinham apenas duas respostas, sim ou não - existe humor na postagem?; existe menção ao partido?. As outras variáveis continham categorias que serão explanadas a seguir.

Os temas gerais foram divididos em seis categorias: 1) Agenda e Informação; 2) Gerenciamento da Imagem Pessoal; 3) Posicionamento Ideológico; 4) Campanha Negativa; 5) Engajamento e Convite à Participação; e 6) Promessas, projetos e políticas públicas. Dentro destes foram criadas subcategorias para garantir uma especificação maior sobre o tema geral, contempladas então pelas variáveis temas específicos e temas secundários. Por exemplo, se um story tinha como tema geral Agenda e Informação, o tema específico teria que estar envolvido com o primeiro, sendo as únicas opções do caso: eventos de campanha, divulgação de notícias e pesquisa de opinião, compartilhamento de HGPE, debates eleitorais e, por fim, dicas de interesse público. O tema secundário não obrigatoriamente tinha relação com o tema geral.

O tipo de imagem foi dividido entre: 1) Foto, quando o story era apenas uma foto sem qualquer tipo de edição; 2) Composição gráfica, para imagens editadas de qualquer forma; 3) MEMES, postagens editadas com algum efeito de humor; 4) Reprodução de material de campanha offline; 5) "Print" (congelamento de tela) e compartilhamento de stories, para postagens que eram apenas reproduções de alguma outra mídia social ou do próprio Instagram; 6) Vídeos e reprodução de links; e 7) Enquetes, que é uma ferramenta disponível no próprio Instagram e que permite a realização de enquetes para os seguidores responderem. 


\subsection{Análise geral dos stories}

Em primeiro momento ilustramos os dados gerais da pesquisa composto pelas variáveis: tema geral, tema específico, tema secundário, tipo de imagem, menção a partido e humor. Em seguida, destacaremos as características presentes em cada uma das candidaturas a partir da análise de resíduos e descrição individual de cada candidato.

No gráfico a seguir de frequência simples (GRÁFICO 1), podemos observar como se deu a distribuição dos temas gerais por candidato. Henrique Meirelles (39\%) e Joao Amoêdo (49\%) priorizaram suas campanhas nos stories voltadas a divulgar ações de agenda de campanha; enquanto os demais voltaram suas atenções a gerenciar sua imagem pessoal, recebendo apoios e destacando aspectos motivacionais. No acumulado, os dois primeiros lugares, "Gerenciamento da Imagem Pessoal" (38\%) e "Agenda e Informação" (34\%), se destacam no total de stories analisados, mostrando que, em princípio, o investimento dos candidatos foi para divulgar eventos de campanha e promoção da imagem pessoal.

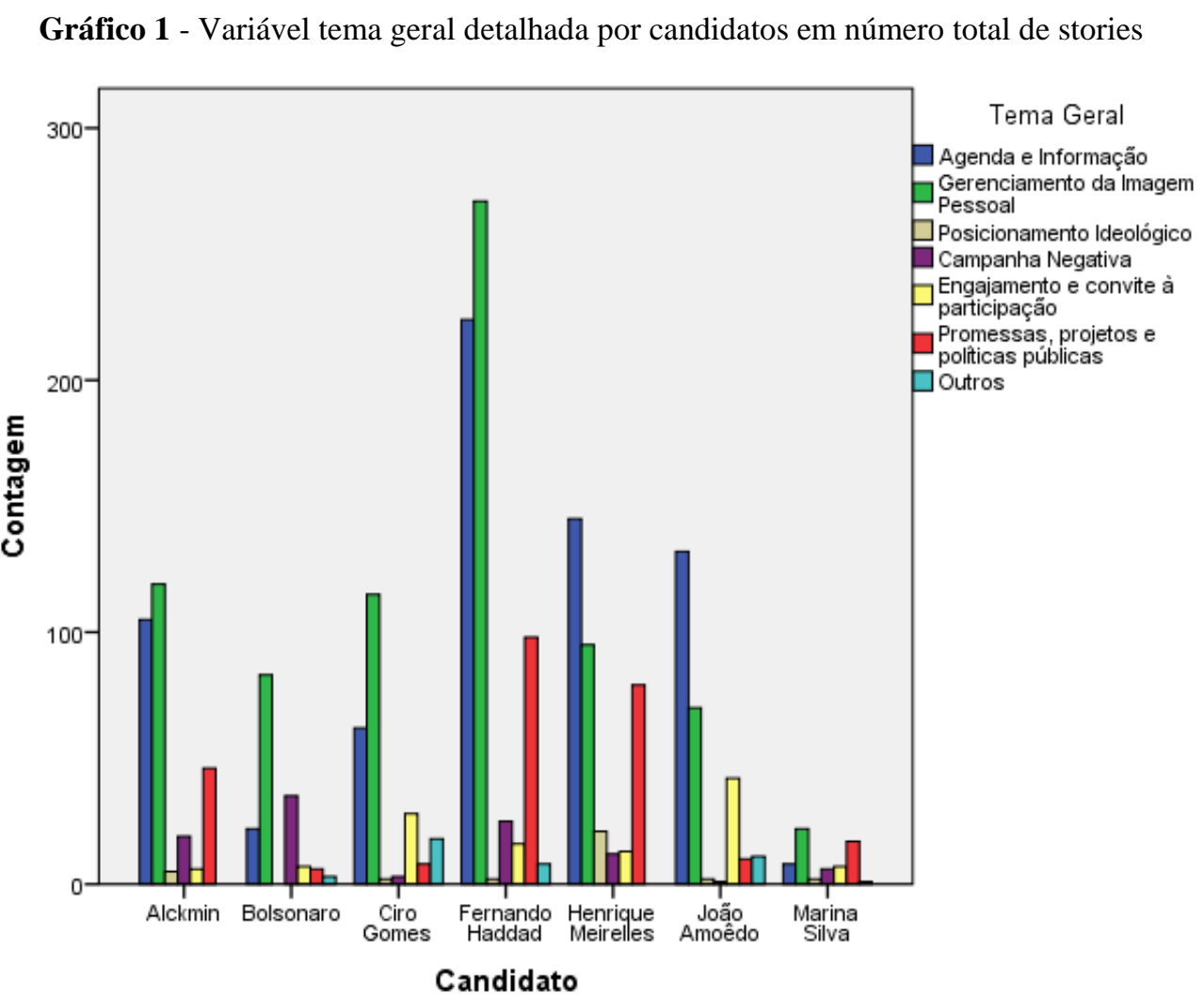

Fonte: Os autores (2019)

Para exemplificar cada um dos temas, trouxemos alguns stories tirados de cada candidato analisado nas duas figuras a seguir. A ordem da sequência apresentada será da esquerda para direita. Primeiro, temos um story de Geraldo Alckmin (PSDB) com o tema 
geral de "Gerenciamento da Imagem Pessoal", isso porque pela frase "Eu não tenho só ficha limpa. Eu tenho vida limpa" o candidato pretende construir uma imagem de político honesto. A segunda figura é de João Amoêdo (NOVO) passando informações sobre onde estará presente em determinada data, então o tema geral foi classificado como "Agenda e Informação". O terceiro story trata sobre propostas do candidato Fernando Haddad (PT), sendo classificado então como "Promessas, projetos e políticas públicas".

Figura 1 - Presença da variável tema geral de Alckmin, Amoêdo e Haddad
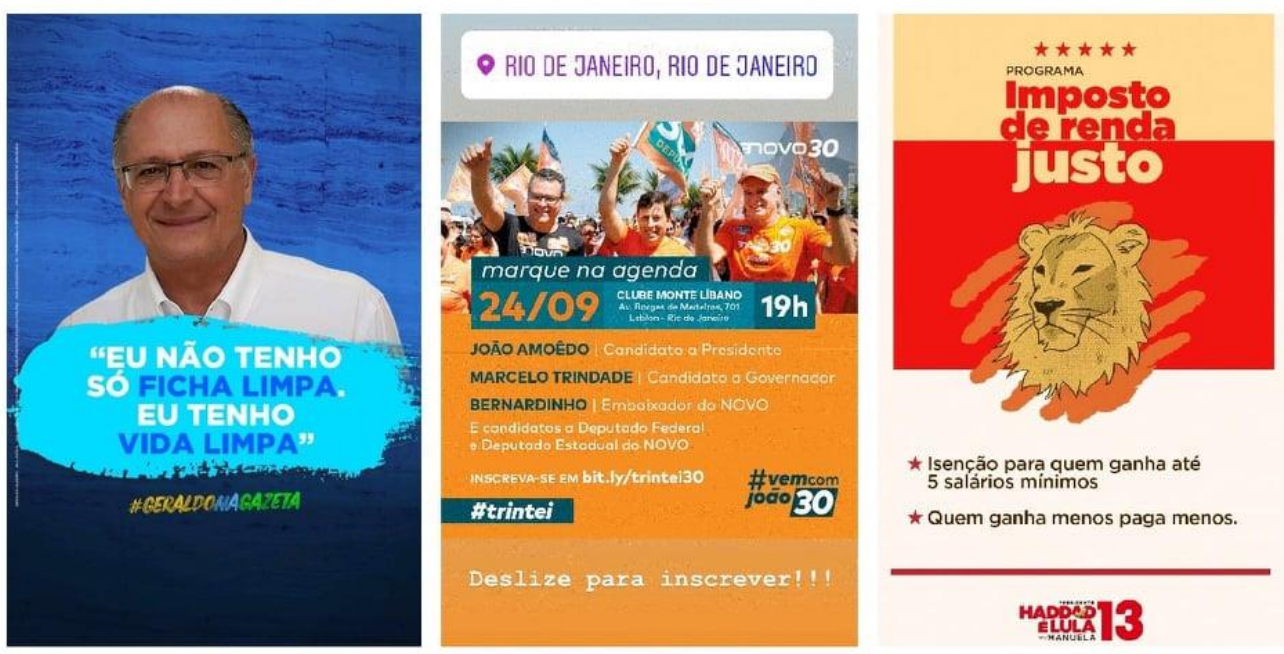

Fonte: Perfis oficiais dos candidatos

A imagem de Ciro Gomes (PDT) é um convite para que seus seguidores e eleitores mudem suas fotos de perfil, demonstrando o apoio ao candidato, sendo assim, ficou como "Engajamento e convite à participação". A postagem de Jair Bolsonaro (PSL) é uma defesa de ataque e, também, um ataque direto ao candidato Geraldo Alckmin, sendo então classificada como "Campanha Negativa". Por fim, temos um story de Henrique Meirelles (MDB), no qual ele se posiciona em relação à desigualdade salarial entre homens e mulheres, sendo um "Posicionamento Ideológico". 
PROGRAMA DE PÓS-GRADUAÇÃO EM COMUNICAÇÃO DA UNIVERSIDADE FEDERAL DE SANTA MARIA

Figura 2 - Presença da variável tema geral de Ciro, Bolsonaro e Meirelles
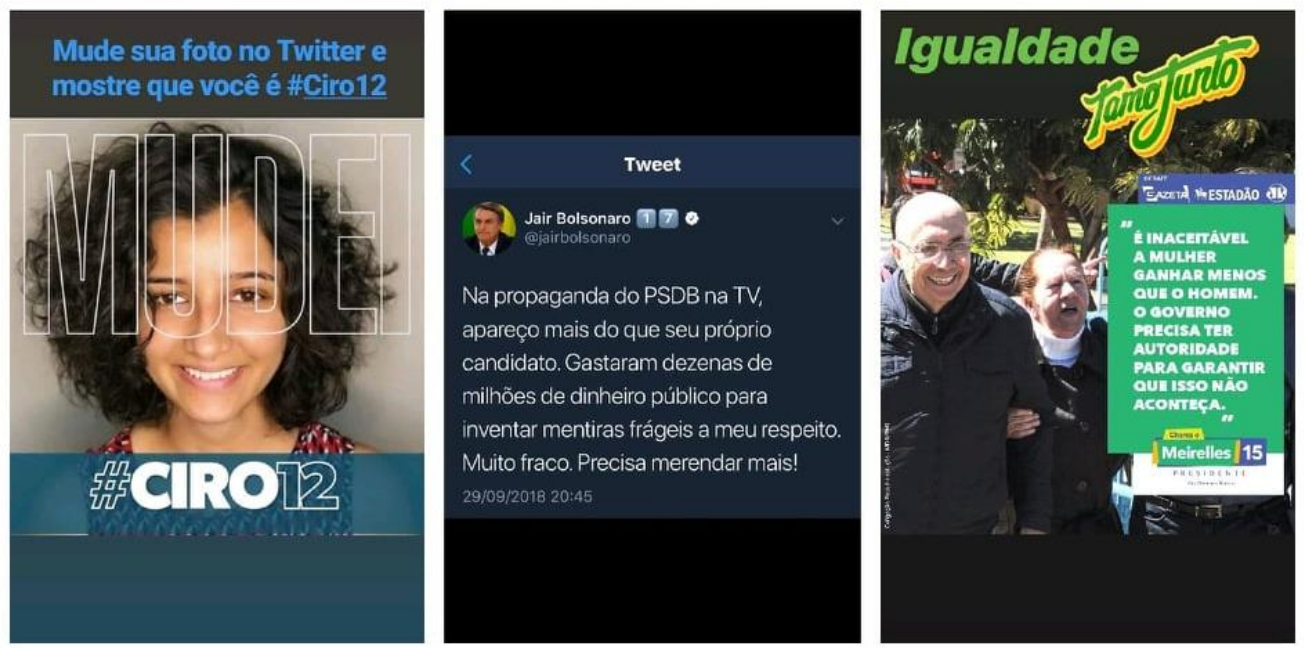

Fonte: Perfis oficiais dos candidatos

Para visualizar mais especificamente o "Tema Geral”, o Gráfico 2 traz a análise de correspondência simples entre tema geral e candidatos (demonstra aproximação das categorias). Este gráfico possibilita melhor visualização da distribuição espacial de cada candidato por tema. O quadrante de análise mostra o que sobressai a partir da visualização de proximidade dos pontos com cores diferentes.

Gráfico 2 - Análise de correspondência

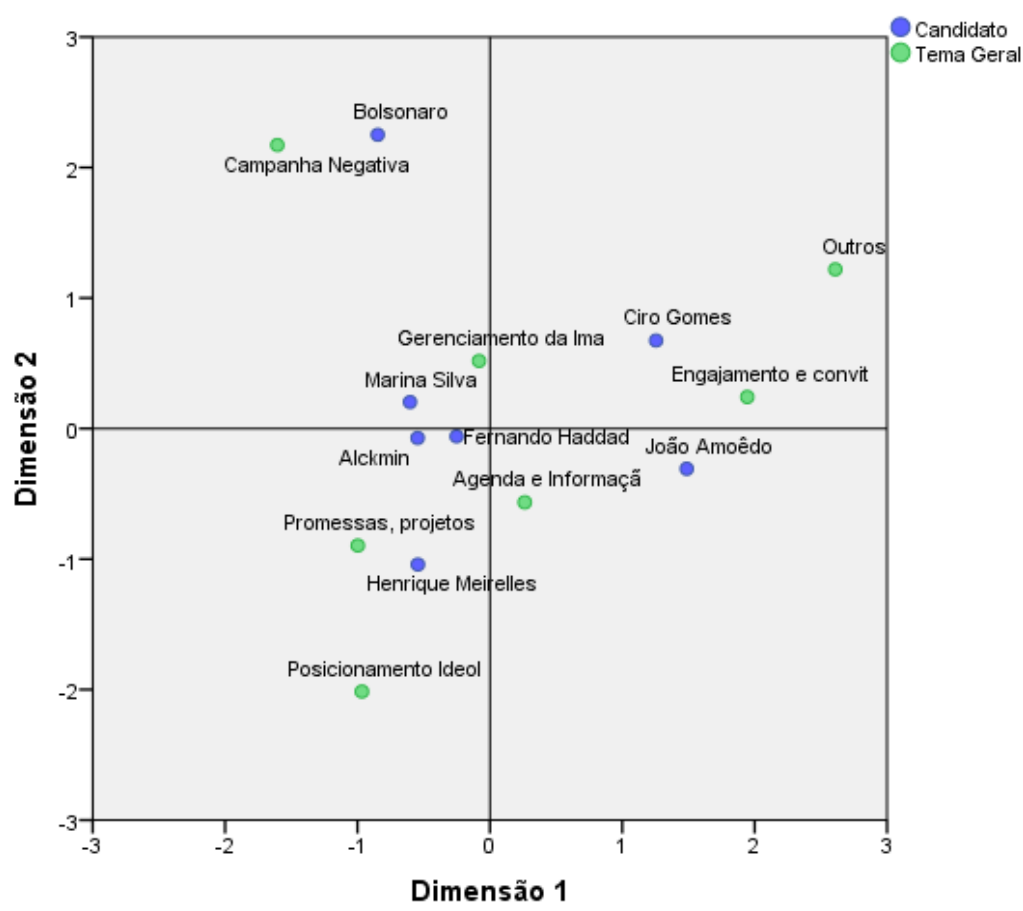

Fonte: Os autores (2019) 
Em seguida, no Gráfico 3 trazemos os temas específicos que apresentaram maior frequência, ou seja, a partir do tema geral desdobramos quais eram os temas específicos presentes dentro do tema geral que prevalece por candidato. No acumulado, eventos de campanha (21\% em Agenda e Informação), apoio de eleitores ao candidato (19\% Gerenciamento da Imagem Pessoal), divulgação de debates, notícias e entrevistas (9\% Agenda e Informação) e realizações anteriores dos candidatos (5,6\% - Gerenciamento da Imagem Pessoal) são destaques entre os candidatos. Os demais temas ficaram abaixo de 5\% e parelhos. Destaque para Fernando Haddad que teve 149 stories publicados sobre eventos de campanha e 138 stories de apoio de eleitores ao candidato.

Gráfico 3 - Variável tema secundário em número total de stories por candidato

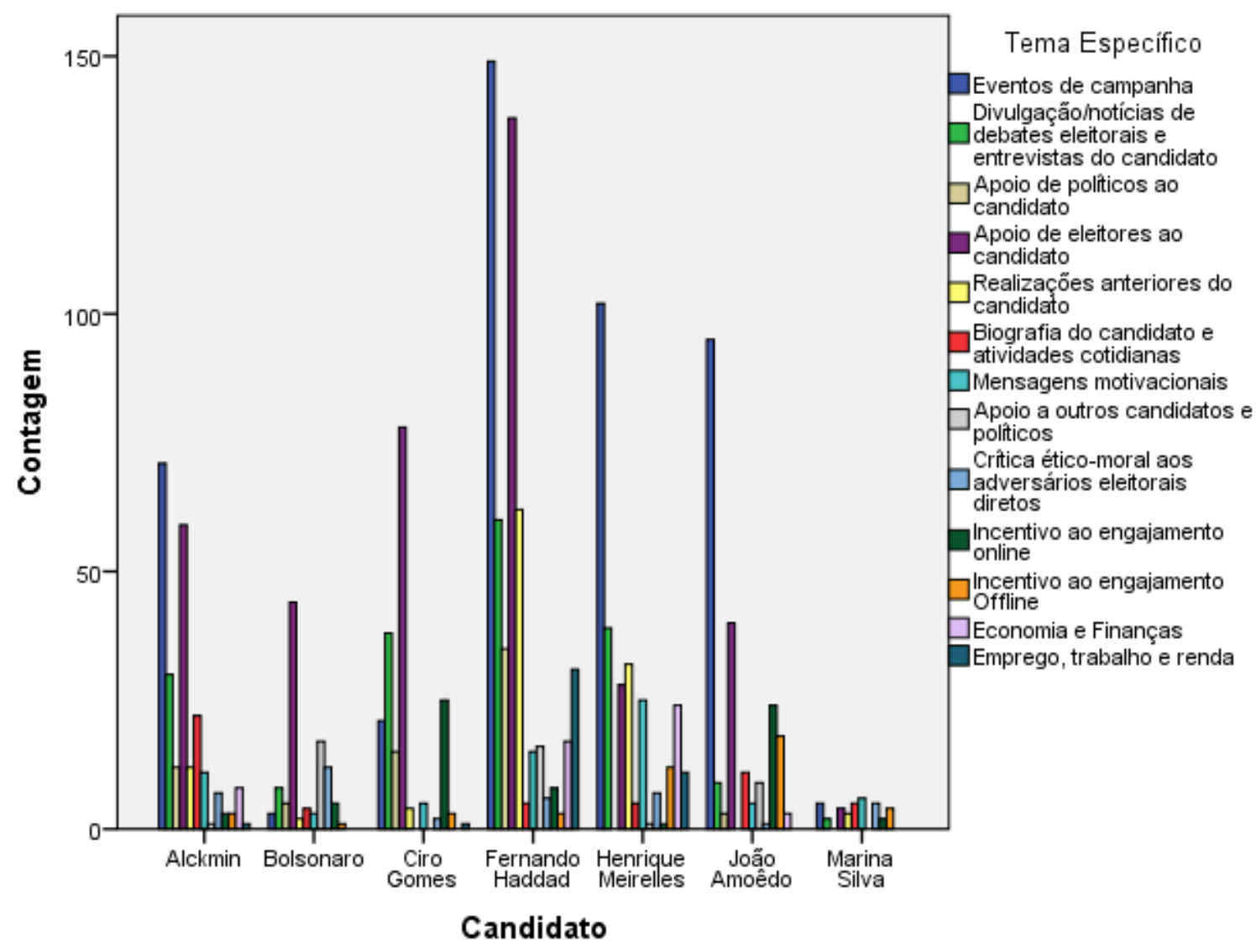

Fonte: Os autores (2019)

A Figura 3 traz como cada um destes quatro principais temas específicos foram interpretados nos stories. O primeiro story, de Marina Silva (REDE), a mostra em um palanque fazendo comício na cidade de Maceió, assim sendo classificado como "eventos de campanha". O "Apoio de eleitores ao candidato" aparece no story de Jair Bolsonaro (PSL), 
sendo apenas uma foto de eleitores com camisetas estampadas com seu rosto e mostrando total apoio para a eleição. No caso da foto de Geraldo Alckmin (PSDB), o candidato está divulgando uma sabatina e, como definido pelo livro de códigos, a única classificação possível é a de "Divulgação/notícias de debates eleitorais e entrevistas do candidato". Por fim, temos um exemplo de "Realizações anteriores do candidato" tirado de um story de Henrique Meirelles (MDB), podemos notar que a ênfase é em realizações anteriores principalmente pela frase descrita.

Figura 3 - Temas específicos em número total de stories por candidato
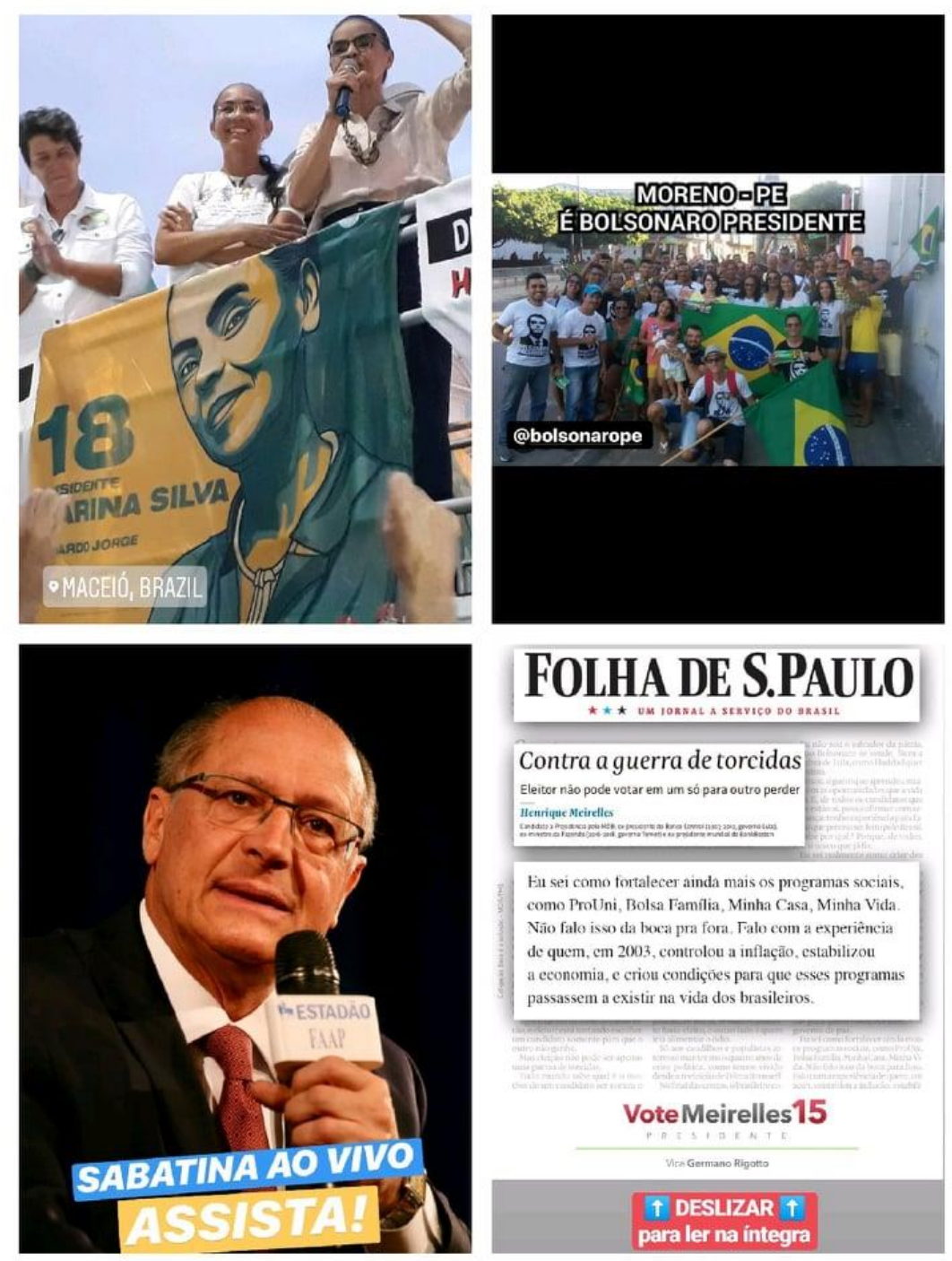

Fonte: Perfis oficiais dos candidatos

O Gráfico 4 não apresenta muitas diferenças em relação ao Gráfico 3. No acumulado, o mais notável é o aparecimento da categoria "Mensagens Motivacionais" em quarto lugar, com quase $10 \%$ das postagens. Eventos de campanha, apoio de eleitores e divulgação de 
notícias, entrevistas e debates prevaleceram como temas secundários aparentes. Lembrando que apenas 968 dos 2033 casos tiveram esta variável preenchida. Fernando Haddad foge da tendência e prioriza dicas de interesse público, assim como Joao Amoêdo que busca demonstrar seu posicionamento sobre a conjuntura nacional.

Gráfico 4 - Variável tema secundário em número total de stories por candidato

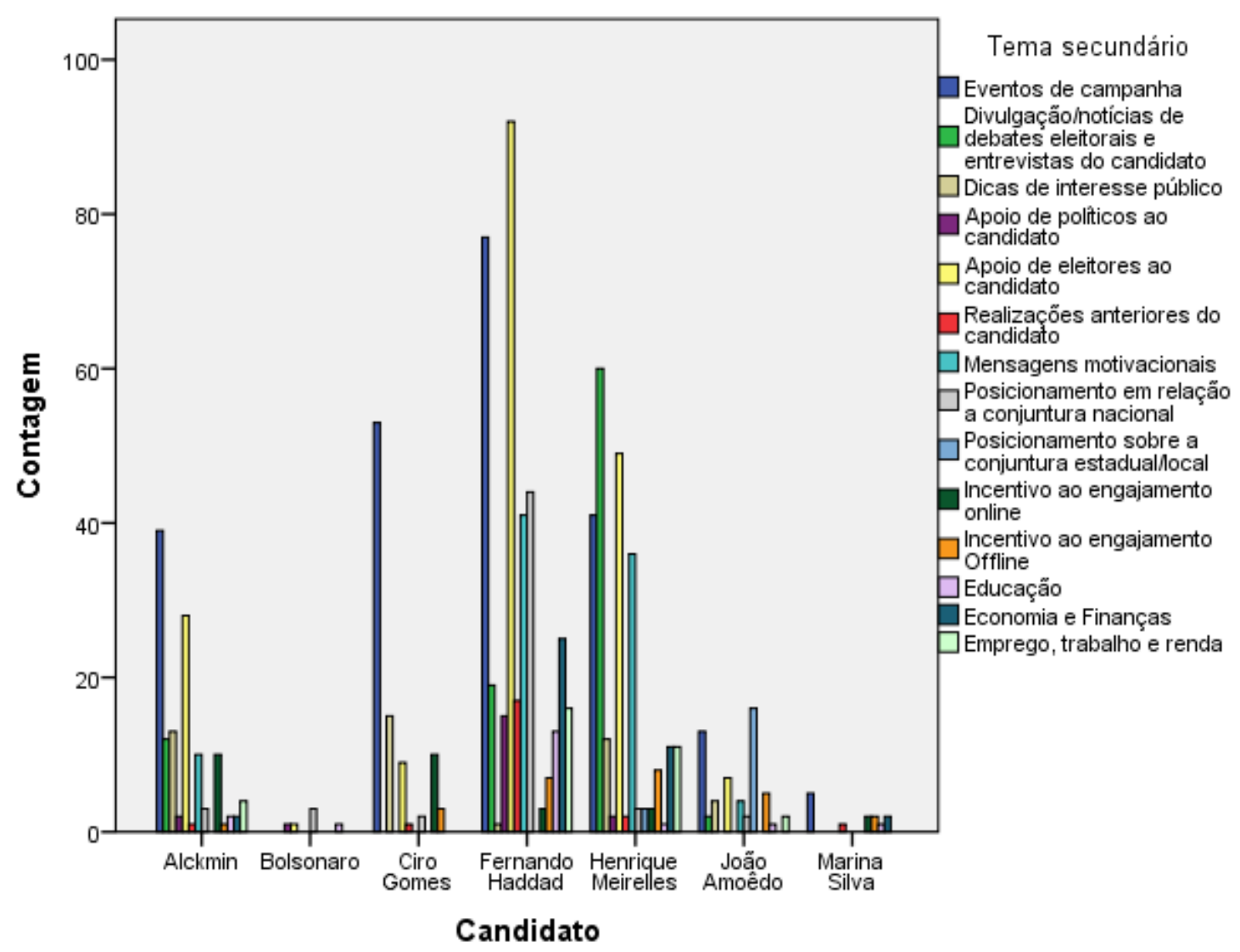

Fonte: Os autores (2019)

O Gráfico 5 mostra como cada candidato utilizou os stories por "Tipo de Imagem". Fernando Haddad, por exemplo, reproduziu expressivamente links e vídeos (85\%). Alckmin e Meirelles seguiram o mesmo caminho. Por sua vez, Ciro Gomes manteve equilíbrio entre uso de fotos e compartilhamento de links e vídeos. Na contramão, Marina ( $\mathrm{N}=34)$ e Amoêdo $(\mathrm{N}=110)$ tiveram prevalência de composição gráfica. No caso de Bolsonaro, houve maior equilíbrio entre o tipo de imagem prevalecendo prints e compartilhamento (28\%) entre os 156 stories. 
Gráfico 5 - Variável tipo de imagem em número total de stories por candidato

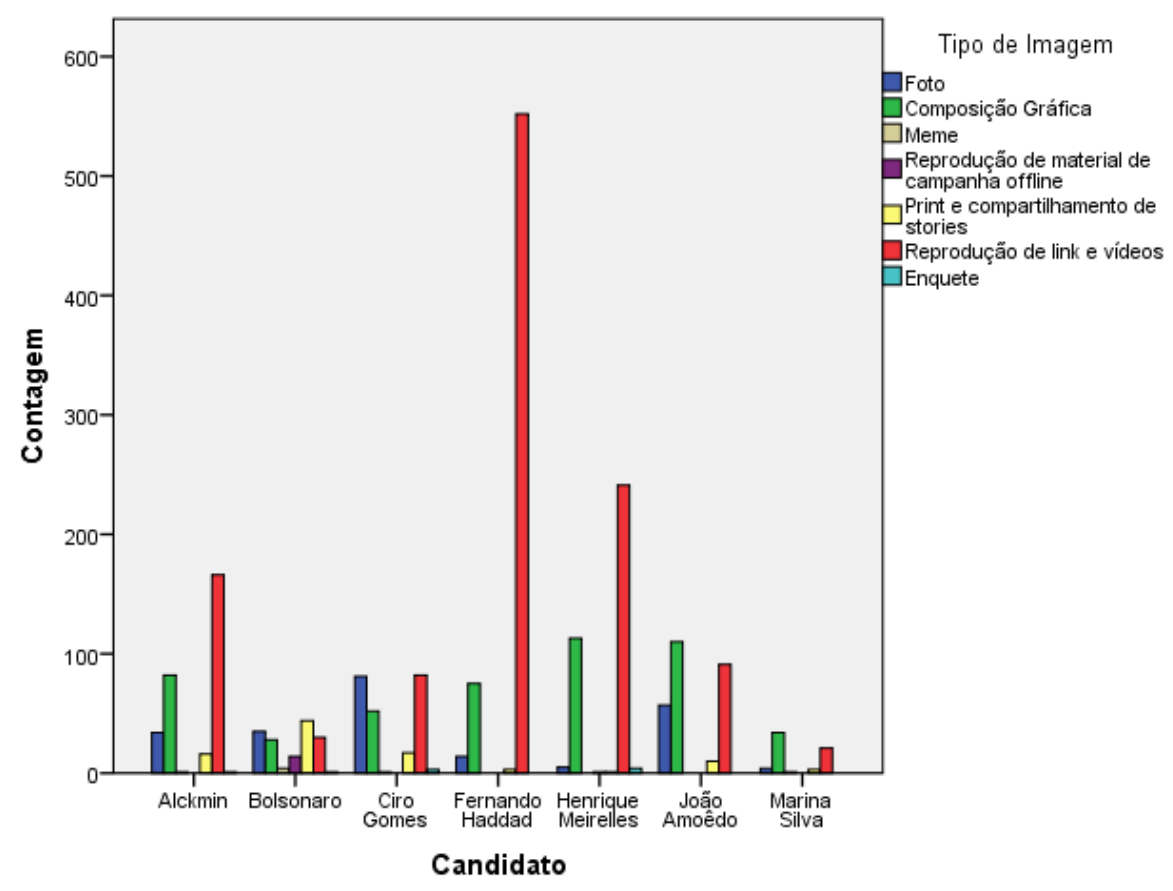

Fonte: Os autores (2019)

Outra variável analisada foi "Menção Partido", a qual nos traz a informação se o candidato mencionou o seu partido nos stories ou não. Como podemos ver no Gráfico 6, houve pouca menção ao partido. Fernando Haddad $(\mathrm{N}=101)$ e João Amoêdo $(\mathrm{N}=77)$ foram os que mais se destacaram. Podemos notar que João Amoêdo tem mais destaque, aproximadamente $28 \%$ dos stories têm menção. Entretanto, a proporção de todos os candidatos é muito baixa. 
Gráfico 6 - Variável menção ao partido em número de stories por candidato

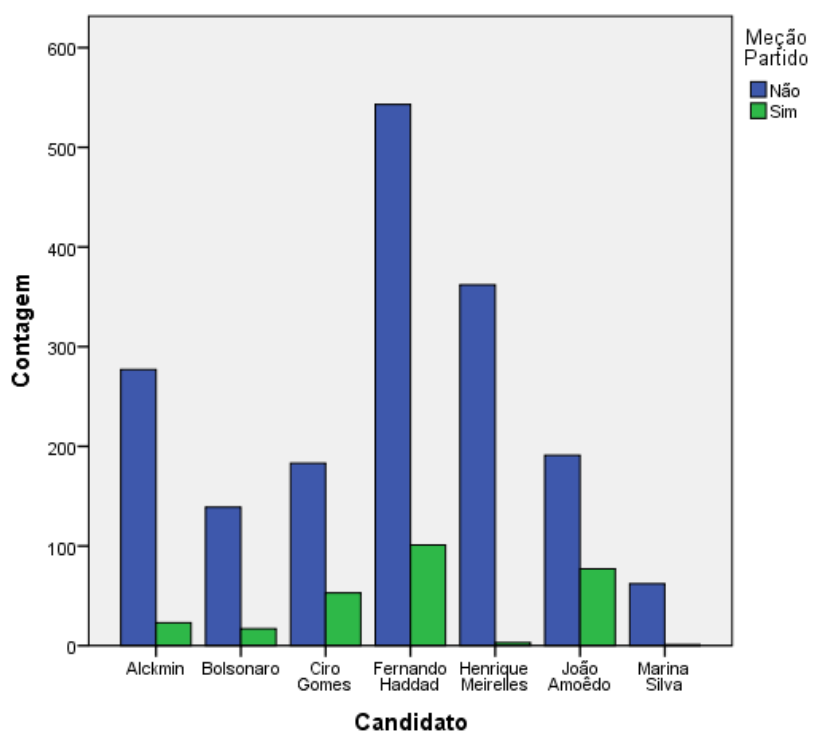

Fonte: Os autores (2019)

O Instagram é uma rede social com diversas funções tendendo a um tom humorístico, como GIFs, figurinhas e filtros com cores e contrastes. Apesar disso, podemos perceber na variável "Humor", pelo Gráfico 7, que os candidatos não utilizaram essa dinâmica para atrair seguidores e eleitores. No acumulado, mais de $90 \%$ dos stories não contaram com a presença do humor.

Gráfico 7 - Variável humor em número total de stories por candidato

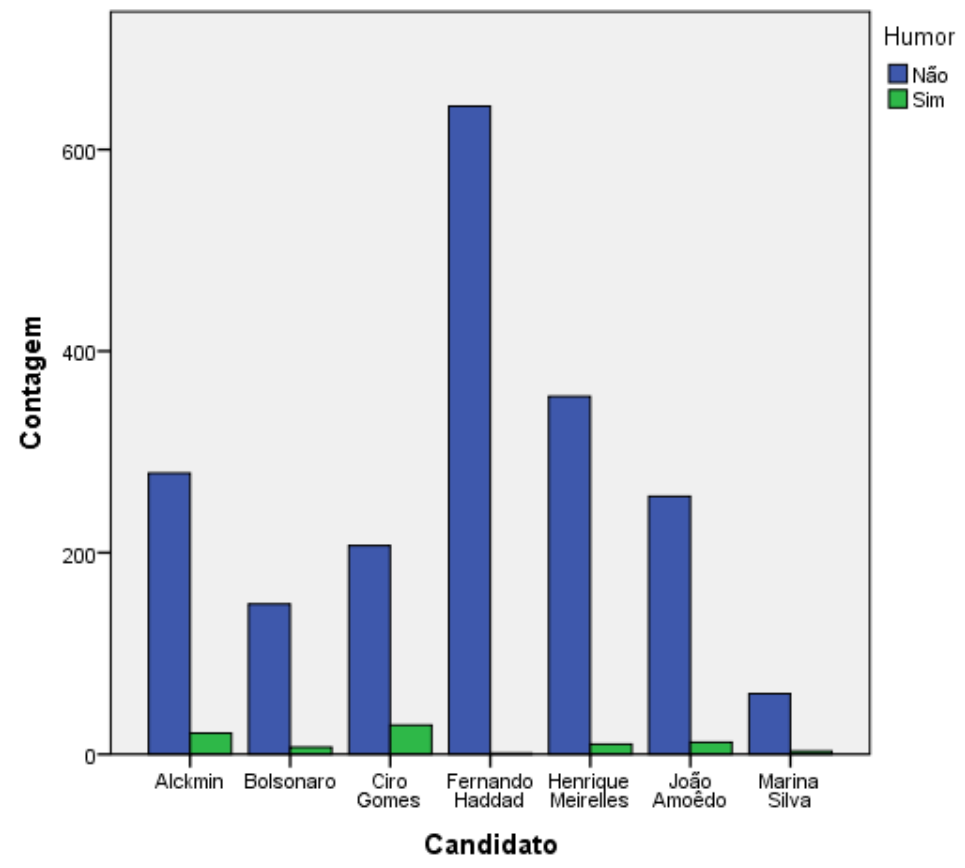

Fonte: Os autores (2019) 
Conforme percebemos, os recursos humorísticos foram pouco utilizados pelas campanhas profissionalizadas dos candidatos. Apesar da plataforma de rede social digital ser utilizada no cotidiano do cidadão como ferramenta de descontração, os candidatos buscaram não envolver emoções e a seriedade foi pilar de sustentação nos stories na campanha eleitoral.

\subsection{Análise específica}

A seguir, apresentamos a análise de resíduos padronizados para, por fim, proceder a uma descrição de cada um dos candidatos na campanha eleitoral para presidente em 2018. A próxima parte de apresentação dos dados foi produzida a partir de uma análise inferencial do corpus, tentando encontrar relações entre a variável "candidato", variável independente, e as variáveis dependentes (tema geral, tema específico, tipo de imagem, menção a partido). Para verificar a construção da imagem dos candidatos nas redes optamos pela realização do procedimento estatístico da análise de resíduos padronizados (demonstra as postagens outliers, aquelas que diferem da maneira que o grupo realiza os stories).

Tabela 3 - Variáveis tema específico vs. candidato

\begin{tabular}{|c|c|c|c|c|c|c|c|c|c|}
\hline \multicolumn{10}{|c|}{ Tabela de cruzamento entre Tema especifico e Candidatos } \\
\hline & & & \multicolumn{7}{|c|}{ Candidato } \\
\hline & & & Alckmin & Bolsonaro & Ciro Gomes & $\begin{array}{c}\text { Fernando } \\
\text { Haddad }\end{array}$ & $\begin{array}{l}\text { Henrique } \\
\text { Meirelles }\end{array}$ & João Amoêdo & Marina Silva \\
\hline \multirow[t]{32}{*}{ Tema Específico } & \multirow[t]{2}{*}{ Eventos de campanha } & Count & 71 & 3 & 21 & 149 & 102 & 95 & $\overline{5}$ \\
\hline & & Std. Residual & 4 & $-5,3$ & $-4,0$ & .5 & 2,2 & 4,9 & $-2,4$ \\
\hline & \multirow[t]{2}{*}{ Divulgação de noticias } & Count & 0 & 7 & 0 & 1 & 0 & 1 & 0 \\
\hline & & Std. Residual & $-1,2$ & 7,7 & $-1,0$ & $-1,1$ & $-1,3$ &,- 2 &,- 5 \\
\hline & \multirow[t]{2}{*}{ Dicas de interesse público } & Count & 0 & 1 & 3 & 1 & 1 & 18 & 0 \\
\hline & & Std. Residual & $-1,9$ &,- 6 & 2 & $-2,4$ & $-1,6$ & 8,4 & -9 \\
\hline & \multirow{2}{*}{$\begin{array}{l}\text { Apoio de artistas e } \\
\text { celebridades ao candidato }\end{array}$} & Count & 0 & 4 & 12 & 0 & 0 & 2 & 4 \\
\hline & & Std. Residual & $-1,8$ & 1,8 & 6,2 & $-2,7$ & $-2,0$ &,- 5 & 4,0 \\
\hline & \multirow{2}{*}{$\begin{array}{l}\text { Apoio de eleitores ao } \\
\text { candidato }\end{array}$} & Count & 59 & 44 & 78 & 138 & 28 & 40 & 4 \\
\hline & & Std. Residual & 0 & 2,7 & 5,3 & 1,1 & $-5,2$ & $-1,5$ & $-2,3$ \\
\hline & \multirow{2}{*}{$\begin{array}{l}\text { Realizações anteriores do } \\
\text { candidato }\end{array}$} & Count & 12 & 2 & 4 & 62 & 32 & 0 & 3 \\
\hline & & Std. Residual & $-1,3$ & $-2,2$ & $-2,4$ & 4,2 & 2,4 & $-3,9$ & -3 \\
\hline & \multirow{2}{*}{$\begin{array}{l}\text { Biografia do candidato e } \\
\text { atividades cotidianas }\end{array}$} & Count & 22 & 4 & 0 & 5 & 5 & 11 & 5 \\
\hline & & Std. Residual & 5,0 & 1 & $-2,4$ & $-2,9$ & $-1,5$ & 1,6 & 2,7 \\
\hline & \multirow{2}{*}{$\begin{array}{l}\text { Apoio a outros candidatos e } \\
\text { políticos }\end{array}$} & Count & 1 & 17 & 0 & 16 & 1 & 9 & 0 \\
\hline & & Std. Residual & $-2,2$ & 7,6 & $-2,2$ &, 5 & $-2,5$ & 1,4 & $-1,2$ \\
\hline & \multirow{2}{*}{$\begin{array}{l}\text { Posicionamento em } \\
\text { relação a conjuntura } \\
\text { nacional }\end{array}$} & Count & 5 & 0 & 1 & 2 & 16 & 2 & 2 \\
\hline & & Std. Residual & .4 & $-1,4$ & $-1,2$ & $-2,3$ & 4,8 &,- 9 & 1,2 \\
\hline & \multirow{2}{*}{$\begin{array}{l}\text { Crítica aos adversários } \\
\text { politicos gerais }\end{array}$} & Count & 2 & 6 & 0 & 1 & 3 & 0 & 0 \\
\hline & & Std. Residual & , 1 & 5,4 & $-1,1$ & $-1,4$ &, 5 & $-1,2$ & -6 \\
\hline & \multirow{2}{*}{$\begin{array}{l}\text { Crítica ético-moral aos } \\
\text { adversários eleitorais } \\
\text { diretos }\end{array}$} & Count & 7 & 12 & 2 & 6 & 7 & 1 & 5 \\
\hline & & Std. Residual & .4 & 5,2 & $-1,1$ & $-1,9$ &,- 1 & $-1,8$ & 3,4 \\
\hline & \multirow{2}{*}{$\begin{array}{l}\text { Crítica a outros atores não } \\
\text { político-eleitorais }\end{array}$} & Count & 1 & 10 & 0 & 6 & 1 & 0 & 0 \\
\hline & & Std. Residual & $-1,0$ & 7,5 & $-1,4$ & , 1 & $-1,3$ & $-1,5$ &,- 7 \\
\hline & \multirow[t]{2}{*}{ Defesa de ataque } & Count & 2 & 6 & 0 & 0 & 0 & 0 & 1 \\
\hline & & Std. Residual & .5 & 6,5 & $-1,0$ & $-1,7$ & $-1,3$ & $-1,1$ & 1,4 \\
\hline & \multirow{2}{*}{$\begin{array}{l}\text { Incentivo ao engajamento } \\
\text { online }\end{array}$} & Count & 3 & 5 & 25 & 8 & 1 & 24 & 2 \\
\hline & & Std. Residual & $-2,3$ &, 0 & 6,4 & $-3,0$ & $-3,2$ & 5,1 & -1 \\
\hline & \multirow{2}{*}{$\begin{array}{l}\text { Incentivo ao engajamento } \\
\text { Offline }\end{array}$} & Count & 3 & 1 & 3 & 3 & 12 & 18 & $\begin{array}{cccccc} & \end{array}$ \\
\hline & & Std. Residual & $-1,4$ & $-1,3$ &,- 8 & $-3,0$ & 1,4 & 5,1 & 2,3 \\
\hline & \multirow[t]{2}{*}{ Economia e Finanças } & Count & 8 & 0 & 0 & 17 & 24 & 3 & 0 \\
\hline & & Std. Residual & 0 & $-2,0$ & $-2,4$ &, 1 & 4,7 & $-1,4$ & $-1,3$ \\
\hline
\end{tabular}


A Tabela $1^{4}$ apresenta o cruzamento das variáveis "Tema Específico" e candidato, com isto é possível visualizar qual presidenciável usou mais ou menos cada tema. Marcamos os resultados mais significativos de cada candidato a partir da contagem de ocorrências e dos resíduos padronizados gerados pelas interações. Com exceção de Fernando Haddad, Geraldo Alckmin e Marina Silva, os outros candidatos tiveram uma maneira diferente no agendamento de temas em seus stories. A seguir, descrevemos um pouco da postura de cada candidato a partir dos dados agregados na pesquisa:

\section{Fernando Haddad}

A prevalência enquanto "Tema Geral" na campanha foram Agenda e Informação (42\%) e Gerenciamento da Imagem Pessoal (34\%). Em relação aos temas específicos destacamos os eventos de campanha (23\%) e apoio de eleitores ao candidato (21\%). Nos temas secundários aparecem os mesmos indicativos. Nos tipos de imagem, Haddad foi o candidato que mais utilizou reprodução de links e vídeos $(85 \%)$ no total de seus conteúdos. Por sua vez, humor e menção ao partido foram pouco relevantes em seus stories, visto o desgaste com a impugnação de Lula e o antipetismo. $\mathrm{O}$ candidato foi o presidenciável que mais utilizou a ferramenta no período analisado. A partir da análise de resíduos padronizados podemos ver também que o uso foi de uma forma mais homogênea em relação aos outros candidatos, com diferenciação apenas no tema "realizações anteriores do candidato". Fernando Haddad (PT) está mais levemente associado a "Promessas, projetos e políticas públicas".

\section{Henrique Meirelles}

Henrique Meirelles (MDB) teve uso de seus stories mais voltados à agenda e informação (39\%), eventos de campanha, enquanto tema específico, prevaleceu (28\%). Por sua vez, divulgação de eventos, debates e entrevistas foi o tema secundário mais presente. Assim como reproduziu mais links e vídeos. Ele teve uma utilização pouco voltada para o

[10] A tabela apresenta apenas os códigos significantes do tema específico, para melhorar a visualização dos dados. 
compartilhamento de apoio dos eleitores ao candidato, centralizando mais para o posicionamento em relação à conjuntura nacional e a divulgação de "Promessas, projetos e políticas públicas" - principalmente em relação à área de economia e finanças. Pela análise de correspondência, Meirelles está mais relacionado a "promessas, projetos e políticas públicas" e levemente a "Posicionamento Ideológico".

\section{Geraldo Alckmin}

Geraldo Alckmin (PSDB), enquanto tema geral, possui destaque em gerenciamento da imagem pessoal, seguido de agenda e informação. Nos temas específico e secundário destacamos eventos de campanha como de maior presença em ambas as análises. Notou-se o uso acentuado de links e reprodução de vídeos, e houve pouco humor ou menção ao partido. Ele possui uma discrepância positiva em suas postagens em relação a "Bibliografia do candidato e atividades cotidianas". Alckmin está associado a "Promessas, projetos e políticas públicas" pela análise de correspondência simples.

\section{Joao Amoêdo}

Na campanha de João Amoêdo (NOVO) prevalece a agenda e informação enquanto "Tema Geral". Nos temas específico e secundário os eventos de campanha ganharam destaque nos stories. A composição gráfica foi o elemento mais presente em suas peças nos stories. Entretanto, Amoêdo foi o candidato que menos deixou de mencionar o seu partido entre todos os presidenciáveis, mostrando ser uma opção diferente dos demais candidatos. Ele possui maior presença no incentivo ao engajamento online e offline, demonstrando um interesse maior na participação dos eleitores.

\section{Ciro Gomes}

Na campanha de Ciro Gomes (PDT) prevaleceu o gerenciamento da imagem pessoal, enquanto "Tema Geral", o apoio de eleitores ao candidato e os eventos de campanha prevaleceram enquanto "Tema Específico" e "Tema Secundário". O candidato foi o único entre todos os candidatos que mais usou fotografias nos stories. O perfil oficial teve uma concentração maior no engajamento online e na divulgação de apoio de eleitores e artistas, 
reforçando uma construção da imagem pessoal positiva e voltada ao apoio. Quanto à análise de correspondência, Ciro está mais associado com "Engajamento e convite à participação".

\section{Jair Bolsonaro}

Jair Bolsonaro (PSL) também teve maior preocupação com o gerenciamento de sua imagem pessoal, enfatizando ainda o apoio de eleitores a sua campanha. Curiosamente ele usou muitos prints e compartilhamento de stories de outros em sua campanha, como forma de campanha negativa. Ele, inclusive, produziu muito mais postagens no campo de "Campanha negativa" que os outros candidatos - tanto atacando outros atores, como se defendendo de ataques.

Concomitante a isso é possível perceber massiva divulgação de notícias. Podemos observar, porém, uma ausência muito maior do que o esperado do tema "eventos de campanha", mas, neste caso, há uma explicação razoável: no dia 6 de setembro (um dia após o começo da coleta dos stories) o candidato sofreu uma facada em um evento de campanha, passando todo o resto da corrida eleitoral se recuperando no hospital ou em casa. $\mathrm{Na}$ correspondência, conseguimos ver Jair Bolsonaro (PSL) mais associado e isolado com "campanha negativa".

\section{Marina Silva}

A candidata Marina Silva (REDE) procurou gerenciar a sua imagem pública, porém as promessas, projetos e políticas públicas foram enfatizados nas suas aparições nos stories. $\mathrm{Na}$ análise específica e secundária, mesmo que bastante difusa em variadas categorias, destacamos eventos de campanha. Marina possui discrepância em relação a "Apoio de artistas e celebridades ao candidato". Em relação à imagem mais usada, Marina teve muito uso de composições gráficas nas suas peças.

Por fim, é possível perceber que mesmo que os candidatos tenham focos diferentes na publicação de seus stories, eles mantiveram um padrão: a utilização para divulgação de bastidores (realizações anteriores, biografia dos candidatos), engajamento (convite parar "correntes" e exposição do apoio dos eleitores) e gerenciamento da imagem pessoal. Desse modo, reforçamos as hipóteses apresentadas na introdução deste artigo. 


\section{CONCLUSÃO}

Numa disputa eleitoral em 2018 acirrada com a ascensão da nova direita, novas regras eleitorais e redução dos dias e tempo no HPGE na TV e rádio, os candidatos necessitaram buscar ambientes digitais para a divulgação de suas narrativas. O Instagram surgiu como ferramenta capaz de propiciar aproximação e engajamento com os cidadãos, porém percebemos que as equipes profissionais de campanha aparentavam não saber como utilizar aquele espaço, com aplicações difusas ao favor das candidaturas. A ferramenta permite driblar os algoritmos e resultar em replicabilidade desde que ocorra a visibilidade de suas ações.

O Instagram é uma plataforma que permite de forma assíncrona, sem imediatismo, persuadir os eleitores pelas mensagens textuais e visuais, sustentadas por um arcabouço de recursos estilísticos e imagéticos. Os rastros deixados pelos stories analisados $(\mathrm{N}=2032)$ permitem constatar que os candidatos enfatizaram enquanto estratégias o gerenciamento de sua imagem pública, destacando os bastidores e agenda de campanha, renegando as propostas de campanha. Essas constatações possibilitam confirmar nossas hipóteses de pesquisa (H1 e H2). Os eventos de campanha e apoios de eleitores aos candidatos representaram $42 \%$ do total de stories entre 40 categorias analisadas no "Tema Específico".

No aspecto negativo, citamos que os projetos, políticas e programas de governo aparecem em pouco mais de $10 \%$ do acumulado. Apenas a candidata Marina Silva (REDE) deu mais destaque a essa categoria. Economia e finanças e emprego, trabalho e renda são os temas primários e secundários, mesmo com aparição ínfima em stories, mais priorizados pelos candidatos quando foram destacados os programas de governo. $\mathrm{O}$ candidato Fernando Haddad (PT) e Geraldo Alckmin (PSDB), pela análise de correspondência, foram os que mais tiveram stories nos seus perfis que associavam projetos, políticos e programas de governo. Haddad, inclusive, produziu o maior número de stories em comparação aos outros candidatos durante o período analisado na campanha eleitoral presidencial de 2018.

$\mathrm{Na}$ contramão, Jair Bolsonaro (PSL) com baixo número de stories $(\mathrm{N}=156)$ usou a campanha negativa para defesa própria e ataque aos demais candidatos. $\mathrm{O}$ candidato aparece ainda na penúltima posição entre os candidatos analisados em quantidade de stories produzidos.

Percebemos, por fim, que apesar do Instagram propiciar uma aproximação com o público, a partir do uso de GIFs, figurinhas e filtros, o uso do humor foi pouco explorado pelos candidatos nos stories. Apenas $10 \%$ dos stories usaram a estratégia comunicacional do 
humor. Os bastidores e agenda de campanha e enaltecimento da imagem pública dos candidatos não contaram com os recursos e características desta plataforma de rede social digital. Além disso, observamos um desprestígio no uso de imagens e textos para enaltecimento do partido e nos ideais do partido. $O$ foco foi nos candidatos e seus posicionamentos políticos, respondendo à questão de pesquisa $(\mathrm{Q} 1)$.

\section{REFERÊNCIAS}

AGGIO, Camilo; REIS, Lucas. Campanha eleitoral no Facebook: usos, configurações e o papel atribuído a esse site por três candidatos eleitos nas eleições municipais de 2012. Revista Compolitica, v. 3, p. 155-188, 2013. Disponível em: http://compolitica.org/revista/index.php/revista/article/view/48. Acesso em: 15 jun. 2019.

BENNETT, W. Lance. News: The Politics of Illusions. 20 ed. New York: Pearson, 2016.

BOSSETTA, Michael. The Digital Architectures of Social Media: Comparing Political Campaigning on Facebook, Twitter, Instagram, and Snapchat in the 2016 U.S.. Journalism \& Mass Communication Quarterly Election, v.1, n. 26, p. 1-26, 2018. Disponível em: https://journals.sagepub.com/doi/full/10.1177/1077699018763307. Acesso em: 26 set. 2019.

BRAGA, Sérgio; CARLOMAGNO, Márcio. Eleições como de costume? Uma análise longitudinal das mudanças provocadas nas campanhas eleitorais brasileiras pelas tecnologias digitais (1998-2016). Revista Brasileira de Ciência Política, v. 26, p. 7-62, 2018. Disponível em: http://www.scielo.br/pdf/rbcpol/n26/2178-4884-rbcpol-26-7.pdf. Acesso em: 10 set. 2019.

BRAGA, Sérgio; WISSE, Fernando; BOZZA, Gabriel. Os partidos políticos brasileiros e as fake news na campanha eleitoral de 2018, p. 109-128. Fake news e as eleições 2018, Cadernos Adenauer XIX, n. 4. Rio de Janeiro: Fundação Konrad Adenauer, p. 168, dez. 2018.

BRUGNANO, Fabrício; CHAIA, Vera. A nova polarização política nas eleições de 2014: radicalização ideológica da direita no mundo contemporâneo do Facebook. Aurora, v. 7, n. 21, p. 99129, out. 2014. Disponível em: https://revistas.pucsp.br/index.php/aurora/article/view/22032. Acesso em: 05 jul. 2019.

CERVI, Emerson Urizzi; MASSUCHIN, Michele Goulart; CARVALHO, Fernanda Cavassana de (Org.). Internet e eleições no Brasil. Curitiba: CPOP, p. 430, 2016.

EKMAN, Mattias; WIDHOLM, Andreas. Political communication in an age of visual connectivity: Exploring Instagram practices among Swedish politicians. Northern Lights, v. 15, p. 15-32, 2017. Disponível em: http://www.ingentaconnect.com/contentone/intellect/nl/2017/00000015/00000001/art00002\#. Acesso em: 26 set. 2019.

FILIMONOV, Kirill; RUSSMANN, Uta; SVENSSON, Jakob. Picturing the Party: Instagram and Party Campaigning in the 2014 Swedish Elections. Social Media + Society, n. 1, v. 11, p. 1-11, ago. 2016. Disponível em: https://journals.sagepub.com/doi/10.1177/2056305116662179. Acesso em: 20 ago. 2019 . 
GLANTZ, Mark. Instagram. In: HARVEY, Kerric (editor), Encyclopedia of social media and politics. Los Angeles, California: Sage Publications, p. 694-696, p. 1608, 2013. Disponível em: http://sk.sagepub.com/reference/encyclopedia-of-social-media-and-politics. Acesso em: 20 jun. 2019.

GOMES, Wilson. Whatsapp e a campanha eleitoral: o que nos espera para 2018. Revista Cult, 29 jun. 2018. Disponível em: https://revistacult.uol.com.br/home/whatsapp-campanha-eleitoral/. Acesso em: 03 jul. 2018.

HU, Yuheng; MANIKONDA, Lydia; KAMBHAMPATI, Subbarao. What We Instagram: A first analysis of Instagram photo content and user types. Eighth International AAAI conference on weblogs and social media, p. 596-598, 2014. Disponível em: https://www.aaai.org/ocs/index.php/ICWSM/ICWSM14/paper/download/8118/8087. Acesso em: 05 jul. 2019.

LALANCETTE, Mireille; RAYNAULD, Vincent. The power of political image: Justin Trudeau, Instagram, and celebrity politics. American Behavioral Scientist, v. 63, n. 7, nov. 2017. Disponível em: https://journals.sagepub.com/doi/abs/10.1177/0002764217744838? journalCode=absb. Acesso em: 25 ago. 2019.

LARREA, Juan José. Comunicación política en latinoamérica: gestión, campañas y tic's. 1 ed. Argentina: Dircom, 2010.

LARSSON, Anders Olof. Top Users and Long Tails: Twitter and Instagram Use During the 2015 Norwegian Elections. Social Media + Society, v. 1, n. 12, p. 1-12, jun. 2017. Disponível em: https://journals.sagepub.com/eprint/hkQGenn5evtwvXHIiZPm/full. Acesso em: 26 set. 2019.

LIEBHART, Karin; BERNHARDT, Petra. Political Storytelling on Instagram: Key Aspects of Alexander Van der Bellen's Successful 2016 Presidential Election Campaign. Media and Communication, v. 5, n. 4, p. 15-25, 2017. Disponível em: https://www.cogitatiopress.com/mediaandcommunication/article/view/1062. Acesso em: 20 ago. 2019.

LÓPEZ-RABADÁN, Pablo; DOMÉNECH-FABREGAT, Hugo. "Instagram y la espectacularización de las crisis políticas. Las $5 \mathrm{~W}$ de la imagen digital en el proceso independentista de Cataluña". El profesional de la información, v. 27, n. 5, p. 1013-1029, 2018.

MARQUES, Francisco Jamil; SAMPAIO, Rafael; AGGIO, Camilo (organizadores). Do clique à urna: internet, redes sociais e eleições no Brasil. Salvador: EDUFBA, 1. ed, 2013.

MUÑOZ, Caroline Lego; TOWNER, Terri L. The Image is the Message: Instagram Marketing and the 2016 Presidential Primary Season. Journal of Political Marketing, v. 16, n. 3-4, p. 290-318, 2017. Disponível em: https://www.tandfonline.com/doi/full/10.1080/15377857.2017.1334254. Acesso em: 20 ago. 2019.

NEWMAN, Bruce L. The mass marketing of politics: democracy in na age of manufactured images. Thousand Oaks, Califórnia: Sage, jul. 1999.

O'CONNELL, David. \#Selfie: Instagram and the United States Congress. Social Media + Society, v. $1, \quad$ n. $17, \quad$ p. $1-17, \quad$ out-dez., $2018 . \quad$ Disponível em: https://journals.sagepub.com/doi/full/10.1177/2056305118813373. Acesso em: 26 set. 2019.

PARMELEE, John H.; ROMAN, Nataliya. Insta-Politicos: Motivations for Following Political Leaders on Instagram. Social Media + Society, v. 1, n. 12, p. 1-12, abr. 2019. Disponível em: https://journals.sagepub.com/doi/full/10.1177/2056305119837662. Acesso em: 12 set. 2019. 
RUEDIGER, Marco Aurelio; GRASSI, Amaro. Redes sociais nas eleições 2018. Rio de Janeiro: FGV DAPP, p. 30, 2018. Disponível em: http://bibliotecadigital.fgv.br/dspace/handle/10438/25737. Acesso em: 26 set. 2019.

RUSSMANN, Uta; SVENSSON, Jakob. How to study Instagram? Reflections on coding visual communication online. PARYCEK, P.; EDELMANN, N. Conference on E-democracy and Open Government, Austria: paper, mai. 2016. Disponível em: http://uu.divaportal.org/smash/record.jsf?pid=diva2\%3A919319\&dswid=4265. Acesso em: 20 jul. 2019.

SCHILL, Dan. The Visual Image and the Political Image: A Review of Visual Communication Research in the Field of Political Communication. Review of Communication, v. 12, n. 2, p. 118 142, abr. 2012. Disponível em: https://www.tandfonline.com/doi/abs/10.1080/15358593.2011.653504. Acesso em: 15 ago. 2019.

SCHMIDBAUER Harald, Rösch Angi; Stieler Fabian. The 2016 US presidential election and media on Instagram: Who was in the lead?. Computers in Human Behavior v. 81, p. 148-160, abr. 2018. Disponível em: https://www.sciencedirect.com/science/article/pii/S0747563217306593. Acesso em: 25 ago. 2019.

SELVA-RUIZ, David; CARO-CASTAÑO, Lucía. Uso de Instagram como medio de comunicación política por parte de los diputados españoles: la estrategia de humanización en la "vieja" y la "nueva" política". El profesional de la información, v. 26, n. 5, pp. 903-915, 2017.

TOWNER, Terri L.; MUÑOZ, Caroline Lego. Picture Perfect? The Role of Instagram in Issue Agenda Setting During the 2016 Presidential Primary Campaign. Social Science Computer Review, v. 5, n. 2, p. $1-16,2017.2$ Disponível em: https://journals.sagepub.com/doi/abs/10.1177/0894439317728222? journalCode=ssce. Acesso em: 25 ago. 2019.

TURNBULL-DUGARTE. Selfies, Policies, or Votes? Political Party Use of Instagram in the 2015 and 2016 Spanish General Elections. Social Media + Society, p. 1-15, 2019. Disponível em: https://journals.sagepub.com/doi/10.1177/2056305119826129. Acesso em: 25 ago. 2019.

WATERLOO, Sophie F., et. al. Norms of online expressions of emotion: Comparing Facebook, Twitter, Instagram, and WhatsApp. New Media \& Society, v. 20, n. 5, p. 1813-1831, mai. 2017. Disponível em: https://journals.sagepub.com/doi/full/10.1177/1461444817707349. Acesso em: 25 ago. 2019.

\section{Original recebido em: 27 de novembro de 2019 \\ Aceito para publicação em: 30 de junho de 2020}

\section{Rafael Cardoso Sampaio}

Professor do Departamento de Ciência Política da Universidade Federal do Paraná (UFPR), do programa de pós-graduação em Ciência Política (PPGCP) e do Programa de Pós-Graduação em Comunicação (PPGCOM) da UFPR, Doutor em Comunicação e Cultura Contemporâneas. Colíder do grupo de pesquisa Comunicação e Participação Política (COMPA-UFPR). 
Professor de Jornalismo e Publicidade e Propaganda do UniBrasil. Professor de Publicidade e Propaganda da PUCPR. Doutorando em Ciência Política pelo PPGCP-UFPR. Membro do COMPA-

UFPR.

Murilo Brum Alison

Mestrando em Ciência Política pelo PPGCP-UFPR. Bacharel em Ciências Sociais pela UFPR. Membro do COMPA-UFPR.

Djiovanni Jonas França Marioto

Mestrando em Ciência Política pelo PPGCP-UFPR. Bacharel em Ciências Sociais pela UFPR. Membro do COMPA-UFPR.

Tiago Philippini Ferreira Borges

da Silva

Mestrando em Ciência Política pelo PPGCP-UFPR. Bacharel em Ciências Sociais pela UFPR. Membro do COMPA-UFPR.

\section{(®) $\odot \Theta(-$}

Esta obra está licenciada com uma Licença

Creative Commons Atribuição-NãoComercial-CompartilhaIgual 4.0 Internacional 